\title{
Canais de distribuição e vantagem competitiva sustentável: uma análise baseada em recursos da firma
}

\author{
Distribution channels and sustained competitive advantage: an analysis \\ based on firm resources
}

\author{
Leonardo Raduy Lemos ${ }^{[a]}$, Ubiratã Tortato $^{[\mathrm{b}]}$
}

[a] Mestre em Administração Estratégica, gerente de marketing da Ferrero do Brasil, Curitiba, PR - Brasil, e-mail: leonardo.raduy@gmail.com

[b] Doutor em Engenharia de Produção, professor do Programa de Pós-Graduação em Administração da Pontifícia Universidade Católica do Paraná (PUCPR), Curitiba, PR - Brasil, e-mail: ubirata.tortato@pucpr.br

\section{Resumo}

Uma rede de distribuição eficiente é frequentemente arrogada como um dos grandes trunfos de alguns líderes de mercado. As decisões correlatas a essa área são estratégicas, de competência das instâncias mais altas das organizações. Ao mesmo tempo, é comum que redes de distribuiç̧ão sejam recursos altamente idiossincráticos, de difícil reprodução por concorrentes. Dentro desse panorama, este artigo faz uma combinação da literatura de administração estratégica e de canais de distribuição, com o objetivo de determinar se e sob que condições uma rede de distribuição eficiente constitui um recurso capaz de gerar vantagem competitiva sustentável. Utiliza-se, como modelo de análise, o modelo baseado em recursos da firma, em que a vantagem competitiva pode ser atribuída à propriedade de um determinado recurso que a habilita a executar certas atividades de forma melhor ou mais barata que seus concorrentes. Conclui-se que uma rede de distribuição eficiente é um recurso capaz de gerar vantagem competitiva sustentável, ao menos no mercado de bens de consumo, desde que a firma disponha dos recursos organizacionais complementares necessários a explorá-lo. O estudo de caso empírico mostrou que a rede de distribuição de um fabricante de balas é provavelmente uma fonte de vantagem competitiva sustentável.

Palavras-chave: Rede de distribuição. Canais de distribuição. Administração estratégica. 


\begin{abstract}
An efficient distribution network is often considered a big advantage of some market leaders. Decisions related to this area are strategic, of responsibility of the highest levels of the organization. At the same time, distribution networks usually are resources highly idiosyncratic, difficult to be reproduced by competitors. Within this context, this article combines strategic management and distribution channels literature, aiming to verify if an efficient distribution network is a resource that is able to generate sustained competitive development, and under what conditions. It is used the model based on firm resources, according to which a sustained competitive advantage may be attributed to the property of a certain resource that enables it to execute specific activities in a better and cheaper way than its competitors. It is found that an efficient distribution network is a resource that is able to generate sustained competitive advantage, at least within consumer goods market, once the firm has the complementary organizational resources that are needed to exploit it. Empirical case study demonstrated that a candy manufacturer distribution network is probably source of sustained competitive advantage.
\end{abstract}

Keywords: Distribution network. Distributions channels. Strategic management.

\section{Introdução}

O campo da administração estratégica procura entender as organizações desde o ponto de vista da alta gestão, buscando compreender e acompanhar as variáveis capazes de gerar vantagem competitiva sustentável. Dentro desse panorama, a visão baseada em recursos tem auxiliado acadêmicos e executivos a interpretar essas variáveis e a formular estratégias de maneira a preparar as organizações para a competição. Esse modelo é particularmente útil na compreensão de como as forças e fraquezas da firma se relacionam com as oportunidades e ameaças ambientais e quais são as condições para que determinados recursos gerem vantagem competitiva sustentável.

Nesse contexto, a gestão de canais de distribuição, também chamados de canais de marketing, é tarefa extremamente importante dentro das organizações, normalmente se tornando preocupação direta da alta gerência. Tal gestão é citada por vários autores como uma das estratégias fundamentais da empresa, capaz de gerar sinergias e agregar valor a partir da redução de custos ou aumento das vendas (ANSOFF, 1988; PORTER, 1988; KOTLER, 1993; KATO,2004). Trabalhando sobre uma realidade sulamericana, Paz (2000) afirma que as empresas que otimizarem a prestação do serviço de distribuição ao menor custo possível conseguirão uma vantagem competitiva sustentável sobre os concorrentes.

Trazendo a questão para o Brasil, é relevante o fato de ser um país muito extenso e disperso, de grande diversidade étnica e cultural. Podem-se observarenormes discrepâncias no desenvolvimento humano e econômico quando se comparam as diferentes regiões do País, e mesmo dentro das mesmas regiões. Essa situação, somada ao custo de vencer as grandes distâncias e os conhecidos problemas de infraestrutura, torna o estudo dos canais de marketing e distribuição uma tarefa ainda mais importante dentro do mix de marketing.

Além desta, este trabalho possui mais cinco seções: a metodologia, a conceituação e importância dos canais de marketing e distribuição; uma revisão teórica do modelo baseado em recursos da firma; a análise da rede de distribuição como recurso da firma; a aplicação do modelo a um caso empírico; e a conclusão.

\section{Metodologia}

O objetivo deste artigo é determinar se e sob que condições uma rede de distribuição eficiente (compreendida como o conjunto de processos, conhecimentos e relacionamentos de uma firma que possibilitam que os seus produtos cheguem ao consumidor final) constitui um recurso capaz de gerar vantagem competitiva sustentável. O delineamento de pesquisa utilizado é descritivo e o método utilizado foi o estudo de caso, a partir da análise documental de dados específicos do setor de doces no Brasil e de entrevistas não estruturadas com profissionais atuantes na gestão de canais de distribuição. De forma complementar, realizou-se também 
a revisão bibliográfica de trabalhos da área de canais de marketing e distribuição.

Os documentos analisados foram obtidos por intermédio de um dos fabricantes do setor e possibilitaram a determinação da cobertura e da participação de mercado de cada um dos fabricantes. Esses dados são obtidos em uma pesquisa do tipo painel, do instituto de pesquisa de mercado AC Nielsen, e estão entre os mais utilizados na aferição do desempenho de mercado em diversos setores. A coleta de dados é realizada em uma pesquisa tipo painel, em que uma amostra fixa de pontos de vendas é pesquisada a cada dois meses. Entre diversas variáveis, o pesquisador verifica a presença de cada produto (a partir da qual é determinada a cobertura), o estoque de cada um deles e o volume comprado em reais. A partir dessas duas últimas variáveis é calculado o valor de vendas de cada produto pesquisado.

A análise documental também possibilitou uma avaliação do nível de investimentos em mídia de cada um deles, por meio de documentos internos do mesmo fabricante gerados a partir de dados do instituto IBOPE de pesquisa de mercado.

Por sua vez, a estrutura de distribuição de cada um dos fabricantes foi determinada a partir de entrevistas não estruturadas com quatro profissionais atuantes na gestão de canais de distribuição de um dos fabricantes, dois deles ex-funcionários de outros fabricantes.

\section{Canais de marketing e distribuição}

Um canal de marketing é um conjunto de organizações interdependentes, envolvidas no processo de disponibilização de bens para uso ou consumo (COUGHLAN etal., 2002). Em geral, as definições de distribuição referem-se ao canal pelo qual os bens fluem da indústria até as mãos do consumidor. À medida que os produtos se tornam menos diferenciados entre si, maior é a busca por eficiências de distribuição.

Os canais de distribuição são formados por brokers, representantes, atacadistas, distribuidores especializados e varejistas. O gerenciamento dos canais de marketing envolve vários tipos de decisão estratégica, desde a formulação da estratégia até a avaliação do desempenho dos membros do canal e gestão de conflitos (ROSEMBLOOM, 2002).

Segundo Paz (2000), os participantes do canal agregam valor ao produto conforme este flui do produtor em direção ao seu consumidor e, nesse percurso, consome recursos que podem variar conformeo tipo de produto e a complexidade do percurso que deve ser percorrido. $\mathrm{O}$ autor afirma que as empresas que aperfeiçoarem a prestação do serviço de distribuição ao menor custo possível conseguirão uma vantagem competitiva sustentável sobre outra empresa.

Segundo Kotler (1993), as decisões sobre os canais de marketing estão entre as mais importantes que uma empresa pode tomar, uma vez que afetam todas as outras decisões de marketing. Alguns autores clássicos da área de estratégia citam a distribuição como uma das estratégias fundamentais da empresa, e não somente da área de marketing. Por exemplo, Ansoff (1988) classifica os canais de distribuição entre aqueles que podem gerar sinergia para a empresa, o que seria um componente fundamental no planejamento estratégico. Porter (1988) atribui grande importância à área de distribuição dentro da estratégia competitiva. Segundo ele, a coordenação e a otimização em conjunto com os canais podem reduzir o custo ou aumentar a diferenciação.

Kato (2004) faz uma revisão de literatura de autores clássicos da área de estratégia e mostra que as decisões acerca das instituições utilizadas na intermediação dos canais de marketing são estratégicas, de competência das instâncias mais altas das organizações.

A pesquisa em canais de marketing e distribuição tem ganhado mais força nos últimos anos. Buscando uma perspectiva histórica, percebe-se que até os anos 1960 toda a pesquisa sobre esse tema era empírica, com o objetivo prático de descrever as funções de atacadistas, distribuidores e varejistas, possibilitando o ganho de eficiências sinérgicas (STERN, 1988).

Stern (1988) comenta que, desde a década de 1980, o estudo do fenômeno "canais de marketing" ganhou bastante força junto à comunidade científica, principalmente em virtude da riqueza dos construtos e paradigmas não cobertos até então e da constatação da importância da gestão dos canais de marketing pelos executivos, interesse talvez despertado pelo deslocamento de poder para os intermediários dos sistemas de distribuição. O mesmo autor diz que os caminhos que deveriam ser trilhados na pesquisa de canais de marketing deveriam se orientar no modelo fornecido pela economia política, porém, combinando variáveis econômicas e comportamentais de maneira holística para o entendimento das interações dentro do canal. 
Rosenbloom e Anderson (1985) propuseram a integração das áreas de gestão de canais e de vendas a partir de cinco das mais básicas interfaces entre essas áreas: a estruturação do canal, a motivação dos seus membros, a sua educação e o seu treinamento, a venda a partir dos seus membros (venda indireta ou "missionária") e a sua avaliação de desempenho. Segundo Mehta, Rosembloom e Anderson (2000), os gestores de vendas, tanto de indústrias de bens de consumo quanto os correspondentes em empresas orientadas industrialmente, são responsáveis pelas tarefas de gestão estratégica dos canais de marketing.

Segundo Weitz e Wang (2004), a separação das atividades de distribuição e produção entre diferentes organizações tem sido a maneira mais eficiente de fazer os produtos chegarem às mãos do consumidor final, com a possível exceção de certas situações idiossincráticas. Ainda assim, mesmo quando essas condições emergem, a verticalização das atividades de distribuição na indústria raramente tem sido efetiva, principalmente no segmento de bens de consumo de alto giro. Assim, é necessário entender os mecanismos de governança da relação entre a indústria e os componentes do canal, sejam eles ligados ao poder assimétrico entre as partes, aos mecanismos de controle contratuais ou ainda às normas implícitas de relacionamento. Também se pode verificar um fenômeno plural de governança, caracterizado pela presença de mais de um mecanismo de governança ao mesmo tempo. O estudo dessas relações é fundamental para a compreensão da distribuição dos produtos ao longo dos diversos canais.

Dentro desse campo do conhecimento, podem-se identificar duas vertentes de estudo:

- vertente econômica: baseada na teoria microeconômica e na teoria dos jogos, que sugere que existem problemas de ineficiência que emergem quando firmas independentes em um relacionamento vertical determinam preços com o objetivo de maximizar seus lucros;

- vertente comportamental: baseada na pesquisa de comportamentos interpessoais e interorganizacionais e das teorias de dependência dos recursos, influência social e gestão estratégica. Essa vertente, durante muito tempo, pesquisou o uso do poder entre as partes para coordenar as atividades do canal e, recentemente, tem passado ao estudo dos mecanismos que possam motivar um comportamento cooperativo entre as partes.

Segundo Frazier e Summers (1984), quando as indústrias utilizam o poder de maneira a impedir que os varejistas atinjam seus objetivos instaura-se uma situação de conflito que, em geral, reflete-se em resultados negativos nos relacionamentos dentro do canal. Dessa maneira, um dos focos desta pesquisa foi como minimizar o conflito resultante do uso do poder.

Nos últimos anos, com a diminuição da assimetria entre os componentes do canal, a vertente comportamental da pesquisa em canais de marketing começou a preocupar-se com os mecanismos que motivam a cooperação entre os membros do canal. No espírito dessa tendência está o comportamento de sacrificar ganhos de curto prazo em detrimento de ganhos mútuos de longo prazo, a partir de duas abordagens: investimentos mútuos idiossincráticos capazes de comprometer as partes, e o desenvolvimento de regras de relacionamento e confiança (WEITZ; WANG, 2004). Em particular, a pesquisa comportamental de canais de marketing preocupa-se também com a natureza das normas escritas e não escritas que governam essas relações (CANNON; ACHROL; GUNDLACH, 2000 apud WEITZ; WANG, 2004).

\section{A visão baseada em recursos}

Segundo Daft (1983 apudBARNEY,1991), a eficácia organizacional pode ser definida em termos de capacidade da organização em explorar seu ambiente na busca de recursos escassos e valiosos. Dessa forma, a firma passaria a controlar esses recursos de maneira a melhorar o seu desempenho em relação aos seus concorrentes.

A visão baseada em recursos enxerga as empresas como conjuntos de ativos e capacidades tangíveis e intangíveis, e a vantagem competitiva pode ser atribuída à propriedade de um determinado recurso que a habilita a executar certas atividades de uma forma melhor ou mais barata que seus concorrentes (COLLINS; MONTGOMERY, 2001).

Dois conceitos são centrais na análise de empresas a partir da visão baseada em recursos. A primeira é a heterogeneidade de recursos, em que firmas 
diferentes possuem conjuntos distintos de recursos; e a segunda é a imobilidade de recursos, em que alguns desses recursos são imóveis, porque copiá-los é muito caro, ou então porque são limitados e têm que ser disputados com as firmas concorrentes (FOSS, 1997; BARNEY, 2001).

Barney (2001) faz ainda uma definição geral de recursos da firma:

são todos os bens, capacidades, competências, processos organizacionais, atributos da firma, informações, conhecimentos, eassim por diante, que são controlados pela firma e a habilitam a conceber e implementar estratégias desenhadas para melhorar sua eficiência e eficácia.

Para possibilitar a análise das firmas no que se refere à capacidade de os seus recursos gerarem uma vantagem competitiva sustentável, Barney (2001) propõe um modelo de análise baseado nos pressupostos de heterogeneidade e imobilidade de recursos. O modelo é estruturado em quatro questões, referentes às atividades de negócios de uma determinada firma em relação a um determinado recurso. Essas questões referem-se a: i) o valor gerado pelos recursos e capacidades no que tange à resposta às ameaças e oportunidades do ambiente; ii) a raridade desse recurso entre as firmas concorrentes em um determinado ambiente; iii) a imitabilidade desse recurso por outras firmas; e iv) a organização em termos de capacidade desenvolvida para explorar esses recursos. Segue análise de cada um desses pontos separadamente.

\section{Recursos valiosos}

Um recurso é considerado valioso se, e somente se, ele é capaz de agregar valor à firma a partir da redução dos seus custos ou do aumento das suas vendas. Nesses casos, um recurso pode habilitar a firma a explorar ou até mesmo criar novas oportunidades no mercado. Caso contrário, pode ser visto como uma fraqueza da firma (BARNEY,2001).

O fato de um recurso ser valioso no presente não significa que sempre o será, uma vez que diversas mudanças ambientais podem acarretar a deterioração do seu valor. Por exemplo, pode-se tomar como base uma indústria de bens de consumo que tenha uma estrutura logística muito eficiente, capaz de distribuir os seus produtos em muitos pontos de venda. Em um cenário hipotético de concentração das cadeias de varejo, combinada com a centralização da sua logística interna, essa estrutura pode se transformar em um recurso sem valor.

Segundo Barney (2001), a firma tem dois caminhos a seguir nesses casos: ou desenvolver novos recursos, adaptados às novas condições ambientais, ou aplicar fortalezas tradicionais de maneiras diferentes. No mesmo caso hipotético da indústria de bens de consumo, ela poderia reagir à mudança ambiental, por exemplo, desenvolvendo uma nova estrutura de controle e gestão para as cadeias de varejo centralizadas, com habilidades diferentes daquelas presentes na estrutura logística, ou então procurar novos canais de distribuição em que a estrutura fosse útil e representasse um recurso valioso.

\section{Recursos raros}

De acordo com Barney (2001), um recurso muito dificilmente será fonte de vantagem competitiva sustentável se for detido por vários competidores em um mercado. Por exemplo, um recurso necessário à implementação de quase todas as estratégias é capacidade de gestão, como descrito por Hambrick (1987). Por outro lado, recursos valiosos mas comuns são fontes de paridade competitiva. Assim, ao avaliar um recurso, deve-se verificar quantos competidores o possuem. O autor observa que pelo fato de não ser raro não significa que um recurso não seja necessário a uma empresa, pois ele pode assegurar a sua sobrevivência. O grau de raridade que necessita para gerar vantagem competitiva sustentável varia, mas, em geral, à medida que o número de firmas que possuem um determinado recurso valioso em um determinado mercado é menor que o número necessário para gerar uma competição perfeita nesse mercado, esse recurso pode ser considerado raro e uma potencial fonte de vantagem competitiva sustentável. Outro ponto a se considerar é que o fato de ser valioso e raro não garante que seja fonte de vantagem competitiva sustentável, mas somente temporária, à medida que outras firmas podem desenvolver o mesmo recurso no decorrer do tempo.

\section{Recursos imitáveis}

Recursos valiosos e raros somente poderão ser fonte de vantagem competitiva sustentável se 
forem imperfeitamente imitáveis, ou seja, se as firmas que não os possuem enfrentarem uma desvantagem em custo ao tentar imitar esse recurso. Essa clonagem pode ocorrer de duas maneiras distintas: pela duplicação direta via aquisição ou desenvolvimento do mesmo recurso ou pela substituição por um outro diferente, mas que gere os mesmo efeitos que o recurso imitado. Existem muitas razões pelas quais um recurso pode gerar uma desvantagem de custo ao ser imitado, algumas das quais são mencionadas a seguir (BARNEY, 1991; BARNEY, 2001; MINTZBERG et al., 2006):

- condições históricas únicas: como oportunidades de aquisição a baixo preço ou o desenvolvimento de recursos sob condições históricas únicas, como, por exemplo, sendo a primeira firma a reconhecer e explorar uma determinada oportunidade, ou então quando adquirem recursos em um período de tempo anterior àquele em que esse recurso tornou-se valioso;

- ambiguidade causal: definida como a situação em que a relação entre a vantagem competitiva de uma determinada firma e o recurso que gera essa vantagem é de difícil compreensão pelas empresas concorrentes, como descrito por Reed e De Fillippi (1990). Nesse caso, podem ser encontrados recursos, como trabalho em equipe da alta gerência, cultura organizacional, relacionamento entre os empregados e com clientes e fornecedores, que podem ser "invisíveis" à concorrência e até mesmo à própria empresa, que pode não saber exatamente qual dos diversos recursos existentes a levaram ao sucesso ou ao fracasso. Ou mesmo pode ser que ele seja resultado de uma complexa combinação de inúmeros fatores, portanto de difícil e cara imitação;

- complexidade social: caracteriza um recurso que para existir depende de uma complexa rede de relacionamentos humanos, além da capacidade de controle e influência da firma, portanto é caro ou mesmo impossível de reproduzir por outra firma. Entre esse tipo de recurso estão as relações interpessoais entre gerentes, a cultura organizacional, a reputação de uma empresa no mercado, entre inúmeras outras coisas;

- patentes: apesar de parecer à primeira vista, não são fontes automáticas de que um recurso é inimitável, ou mesmo de que o custo de imitação será mais alto. Em determinados casos, o processo formal requerido pelo processo de patenteamento pode revelar ao mercado detalhes importantes do processo ou produto patenteado, o que pode diminuir o custo de imitação por concorrentes.

\section{A organização}

Barney (2001) ainda acrescenta uma última questão à análise da capacidade de um recurso da firma em gerar uma vantagem competitiva sustentável, que é a capacidade organizacional da firma em explorar esse recurso. Assim, a firma deve estabelecer recursos e capacidades complementares, incluindo a estrutura formal de reporte, os sistemas de controles explícitos e as políticas de remuneração, que sozinhos são incapazes de gerar uma vantagem competitiva sustentável, mas que, se aplicados em conjunto com recursos capazes de explorar oportunidades ou neutralizar ameaças do ambiente, permitem à firma explorar esses recursos e obter uma vantagem competitiva sustentável.

\section{A distribuição como recurso da firma}

O conjunto de processos, conhecimentos e relacionamentos de uma firma que possibilitam que esta tenha acesso à sua rede de distribuição constituem um recurso da firma. Neste artigo, com o propósito de simplificação, esse conjunto será definido simplesmente como "rede de distribuição". Tal rede abarca a estrutura formal de gestão de canais de distribuição localizada no interior de uma firma, bem como os parceiros envolvidos nas tarefas de distribuição, ou seja, que possibilitem a chegada de um produto até as mãos do consumidor final (MEHTA; ROSEMBLOOM; ANDERSON, 2000). Entre esses parceiros incluem-se distribuidores, atacadistas, comerciantes e representantes (ROSEMBLOOM; ANDERSON, 1985; PAZ, 2000; DIAS, 1993). Indo além desses conceitos, a maneira 
com que os produtos chegam ao consumidor final também deve ser considerada na rede de distribuição de uma firma. Nesse caso, elementos como a maneira com que um produto é exposto em um ponto de vendas, a importância atribuída por vendedores a ele e o valor agregado pelo próprio local de distribuição fazem parte da rede de distribuição de uma firma.

Assim, essa rede pode ser compreendida como um recurso organizacional, uma vez que compreende um subconjunto de indivíduos controlados pela firma, responsáveis por conceber e implementar estratégias de distribuição, que são tarefas com o objetivo de melhorar a eficiência da firma. Isso porque, para ser adquirido, um bem deve estar disponível, e (com algumas exceções) quanto mais facilmente possa ser encontrado maior a probabilidade de que um determinado produto venha a ser adquirido. Uma maior eficiência também pode ser obtida a partir da minimização do custo da realização dessas tarefas.

Analisando a rede de distribuição à luz do presente modelo teórico, o seu valor para uma firma é inestimável, uma vez que ela é necessária para que os seus produtos cheguem ao consumidor final. Uma rede de distribuição que possibilite uma cobertura adequada habilita a firma a explorar as oportunidades de demanda que os seus produtos possuem, pois permite a chegada do produto às mãos do consumidor final e, da maneira adequada, à sua correta percepção de valor. De maneira inversa, uma rede de distribuição pode também reagir a ameaças ambientais, seja combatendo lançamentos de concorrentes, seja identificando mudanças ambientais nos canais de distribuição e auxiliando a firma a adaptar-se a elas. Claramente, é muito mais fácil reagir a um lançamento de um concorrente detendo uma distribuição adequada. Como exemplo, Barney (2001) cita a defesa da Coca-Cola ${ }^{\circledR}$ contra a Pepsi ${ }^{\circledR}$, no mercado americano, em que um dos recursos que auxiliou a sua defesa foi um "excelente sistema de distribuição".

Certamente, a rede de distribuição é um recurso beterogeneamente distribuido entre as diversas firmas, pois, ainda que tenhamos um mercado extremamente regulado, em que todos os competidores sejam distribuídos nos mesmos canais e de maneira muito uniforme, a qualidade e a forma de relacionamento entre os componentes do canal e os funcionários da firma será diferente, seja em função das diferentes culturas organizacionais presentes em diferentes firmas, seja em função das diferenças de força das marcas, ou mesmo da diversidade dos próprios produtos, que implicam maneiras diferentes de chegada ao consumidor.

Dependendo do mercado a que se faça referência, uma rede de distribuição também pode ser um recurso com um considerável nível de imobilidade (ANDERSON; DAY; RANGAN, 1997). Por exemplo, em mercados de produtos de consumo de alto giro os dois pressupostos de imobilidade estão presentes na rede de distribuição, já que se essa rede for eficiente será cara de copiar, pois pressupõe que um produto chega a muitos pontos de venda ao mesmo tempo, da maneira mais econômica possível e isso pode custar muito em termos de estrutura interna, da contratação de parceiros externos ou da combinação dos dois. Ao mesmo tempo, a capacidade dos componentes dos canais de distribuição de bens de consumo é limitada, pois os pontos de venda possuem um determinado espaço, de difícil expansão, e os distribuidores e atacadistas possuem também uma capacidade limitada de gestão em termos de número de produtos comercializados. Nesse último caso, a limitação pode ser tanto de ordem física (armazéns, meios de transporte, etc.), organizacional (número de vendedores, pessoal administrativo, faturamento, etc.) ou financeira (gestão do fluxo de caixa para manutenção de inventários).

No que tange à raridade, uma rede de distribuição em si não é um recurso raro na maioria dos mercados existentes, mas uma rede realmente eficiente em termos de custo e que leva os produtos da firma a um conjunto de pontos de vendas que permita o aproveitamento total do potencial dos seus produtos, sendo um recurso certamente detido por poucas firmas. Em particular, quando falamos de mercados de bens de consumo, essa situação tornase mais clara, dado o grande número de pontos de vendas que representam o potencial total de vendas desse tipo de produto.

Em termos de imitabilidade, uma rede de distribuição tende a ser um sistema difícil e caro de imitar, principalmente em mercados de bens de consumo de alto giro, pela complexidade social que tende a ter, uma vez que nesses casos é necessário fazer os produtos chegarem a uma grande quantidade de consumidores, por meio de vários níveis de canais.

Conforme se encontra em Weitz e Wang (2004), para entender os mecanismos relacionais dentro dos canais de distribuição, é necessário entender os mecanismos de governança da relação entre a indústria e os componentes do canal, sejam eles ligados ao poder assimétrico entre as partes, aos mecanismos 
de controle contratuais ou ainda às normas implícitas de relacionamento. Também se pode verificar um fenômeno plural de governança, caracterizado pela presença de mais de um mecanismo de governança ao mesmo tempo. Dessa maneira, a completa compreensão do recurso denominado rede de distribuição é uma tarefa muito complexa, por tratar-se de fenômenos organizacionais, conforme o argumento de Stern (1988), e portanto a sua imitabilidade tende a ser muito cara e difícil, não somente em termos de recursos financeiros, mas também em termos de tempo.

Em determinadas situações, pode também haver uma situação histórica única que possibilita a formação de uma rede eficiente de distribuição e que pode não ser reprodutível no presente. Outro fator pouco compreendido é a relação causal entre força de marca e força de distribuição. Muitas marcas com grande participação de mercado possuem força distributiva muito forte (pode-se pensar em marcas como CocaCola ${ }^{\circledR}$, Faber Castell ${ }^{\circledR}$, entre várias outras), mas é difícil distinguir até que ponto o nível de distribuição influencia a participação de mercado ou que a própria participação de mercado influencia a distribuição. As indicações do presente são de que as fortalezas de participação de mercado e distribuição apoiam umas às outras na sua sustentação, mas as relações causais se confundem a ponto de ser difícil dimensionar qual o potencial para uma marca que queira replicar a rede de distribuição de outra marca, considerando-a fonte de vantagem competitiva e buscando a paridade competitiva.

Como complemento à análise, para que a rede de distribuição gere uma vantagem competitiva sustentável, a firma deve ter recursos e capacidades complementares que permitam que essa rede de distribuição explore as oportunidades ou neutralize as ameaças ambientais. Além da estrutura formal de reporte, dos sistemas de controles e das políticas de remuneração já mencionados anteriormente, outros recursos complementares poderiam ser: campanhas publicitárias que incitem o consumidor final a consumir os produtos disponíveis nos pontos de vendas; estruturas de análise do mercado, com vistas a determinar os melhores instrumentos de exposição nos pontos de vendas; e, ainda, capacidades de projeto e confecção desses instrumentos com a velocidade e o nível de preço compatíveis com os objetivos da firma.

A integração das partes do modelo mostra que, ao menos em mercados de bens de consumo de alto giro, uma rede de distribuição eficiente é um recurso que gera vantagem competitiva sustentável.
É um recurso heterogeneamente distribuído e, dentro de certos limites, imóvel, e ainda é valioso, raro e imperfeitamente imitável. Assim, se a firma tiver a capacidade organizacional de explorá-lo, será uma fonte de vantagem competitiva sustentável.

Retornando à análise do modelo, podemse também citar alguns casos em que uma rede de distribuição eficiente não é fonte de vantagem competitiva sustentável, como em mercados quase monopolistas, em que o fato de melhorar a abrangência de distribuição não geraria valor adicional à empresa em termos da competição com outras empresas. Ou então mercados muito regulados, em que os competidores são poucos e estão presentes em todos os pontos de vendas possíveis.

\section{Aplicação do modelo teórico a um caso empírico}

Este estudo considera cinco fabricantes de doces com atuação nacional que concentram quase $90 \%$ do faturamento do mercado, concentrando atenção sobre a categoria de balas. $\mathrm{Na}$ Tabela 1 , encontra-se a participação de mercado de cada fabricante, em valor, durante cada bimestre entre outubro/novembro de 2003 e outubro/novembro de 2006. Nessa tabela, pode-se perceber que o fabricante "E" é líder absoluto de mercado, com mais de $50 \%$ de participação.

$\mathrm{Na}$ Tabela 2, pode-se encontrar a cobertura do mercado de cada um dos fabricantes a cada bimestre auditado, em percentual do total de lojas presentes no mercado, e também análises de correlação realizadas entre a participação de mercado em valor e a cobertura de cada um dos fabricantes. A primeira análise toma, a cada período pesquisado, a correlação entre a participação de mercado de todos os fabricantes e a sua respectiva cobertura. O seu objetivo é determinar se os fabricantes com maior cobertura possuem também maior participação de mercado. A segunda análise verifica, para cada fabricante, a correlação entre a cobertura e a participação de mercado, com o objetivo de determinar se a variações da primeira correspondem às variações concomitantes da segunda.

A análise da Tabela 2 mostra uma participação de mercado fortemente correlacionada com a cobertura quando se tomam todos os fabricantes a cada período (valores de correlação entre 0,857 e 
0,895). A associação entre variações de cobertura e participação de mercado para cada fabricante é muito menos evidente. Essa associação fortemente positiva entre a cobertura e a participação de mercado mostra que não se pode rejeitar o pressuposto de que uma estrutura de distribuição que gere alto nível de cobertura do mercado é uma fonte de vantagem competitiva sustentável. Especificamente, o fabricante "E", que possui a maior cobertura (próxima de 60\%), é também líder de mercado com larga margem em relação aos demais competidores (mais de $50 \%$ do mercado). Além disso, para três dos fabricantes ("A", "D" e "E"), quanto maior o nível de cobertura do fabricante maior é a sua participação de mercado em valor. Os fabricantes "B" e "C", mesmo com cobertura inferior à dos fabricantes "D" e "A", respectivamente, possuem menor participação em valor, aparentemente compondo uma objeção à inferência realizada nesta análise. Contudo, um exame da estratégia de preço mostra os fabricantes "B" e "C" como competidores de preços inferiores à média do mercado. Essa é a razão da sua menor participação de mercado, mesmo com uma cobertura maior.

A segunda análise de correlação, em que se procura quantificar o impacto de variações da cobertura na participação de mercado, gera inferências bastante diferentes. Para três dos fabricantes ("B", "D" e "E"), encontram-se correlações moderadas; para o fabricante "C", correlação forte $(0,894)$; e, para o fabricante "A", fraca $(0,169)$. Um resumo desses últimos resultados pode ser visto na Tabela 3.

Tabela 1 - Participação de mercado, em valor, dos cinco maiores fabricantes de balas no Brasil. Valores em percentual do total. Áreas auditadas: todo o País, exceto MT, PI, MA e região Norte

\begin{tabular}{lccccc}
\hline & $\begin{array}{c}\text { Fabricante A } \\
\text { \% }\end{array}$ & $\begin{array}{c}\text { Fabricante B } \\
\text { \% }\end{array}$ & $\begin{array}{c}\text { Fabricante C } \\
\text { \% }\end{array}$ & $\begin{array}{c}\text { Fabricante D } \\
\%\end{array}$ & $\begin{array}{c}\text { Fabricante E } \\
\%\end{array}$ \\
\hline Out/nov 2003 & 13,7 & 5,2 & 8,8 & 9,4 & 55,8 \\
Dez/jan 2004 & 14,6 & 5,6 & 8,4 & 8,4 & 56,0 \\
Fev/mar 2004 & 14,2 & 5,4 & 7,5 & 8,3 & 57,6 \\
Abr/mai 2004 & 14,1 & 5,5 & 8,4 & 8,2 & 56,7 \\
Jun/jul 2004 & 13,6 & 5,3 & 10,0 & 8,7 & 55,5 \\
Ago/set 2004 & 14,0 & 5,0 & 9,7 & 8,2 & 55,9 \\
Out/nov 2004 & 14,1 & 4,8 & 9,0 & 8,9 & 55,0 \\
Dez/jan 2005 & 15,3 & 4,9 & 8,3 & 7,8 & 54,5 \\
Fev/mar 2005 & 15,6 & 5,6 & 7,8 & 7,5 & 54,4 \\
Abr/mai 2005 & 15,2 & 5,3 & 8,5 & 7,2 & 54,6 \\
Jun/jul 2005 & 14,5 & 5,2 & 8,2 & 7,5 & 52,3 \\
Ago/set 2005 & 14,7 & 5,4 & 8,6 & 8,0 & 50,9 \\
Out/nov 2005 & 14,5 & 9,5 & 8,3 & 52,1 \\
Dez/jan 2006 & 14,1 & 5,3 & 10,1 & 8,1 & 53,2 \\
Fev/mar 2006 & 13,8 & 5,2 & 9,9 & 8,2 & 53,0 \\
Abr/mai 2006 & 14,3 & 5,5 & 9,5 & 8,4 & 52,9 \\
Jun/jul 2006 & 14,7 & 5,2 & 9,5 & 8,5 & 52,2 \\
Ago/set 2006 & 13,9 & 5,1 & 9,5 & 9,3 & 53,4 \\
Out/nov 2006 & 12,7 & 4,9 & 4,6 & & \\
\hline
\end{tabular}

Fonte: INSTITUTO, 2006. 
Tabela 2 - Cobertura em percentual do número de lojas dos cinco maiores fabricantes de balas no Brasil e correlação entre a participação de mercado e a cobertura, a cada período e para cada fabricante (áreas auditadas: todo o País, exceto MT, PI, MA e região Norte)

\begin{tabular}{|c|c|c|c|c|c|c|}
\hline & $\begin{array}{c}\text { Fabricante A } \\
\%\end{array}$ & $\begin{array}{c}\text { Fabricante B } \\
\%\end{array}$ & $\begin{array}{c}\text { Fabricante C } \\
\%\end{array}$ & $\begin{array}{c}\text { Fabricante D } \\
\%\end{array}$ & $\begin{array}{c}\text { Fabricante } \mathbf{E} \\
\%\end{array}$ & $\begin{array}{c}\text { Correlação } \\
\text { participação/ } \\
\text { cobertura }\end{array}$ \\
\hline Out/nov 2003 & 20 & 30 & 30 & 16 & 61 & 0,897 \\
\hline Dez/jan 2004 & 20 & 31 & 30 & 16 & 60 & 0,886 \\
\hline Fev/mar 2004 & 20 & 31 & 28 & 16 & 60 & 0,897 \\
\hline Abr/mai 2004 & 20 & 31 & 30 & 15 & 59 & 0,880 \\
\hline Jun/jul 2004 & 20 & 32 & 32 & 16 & 59 & 0,868 \\
\hline Ago/set 2004 & 21 & 31 & 32 & 15 & 57 & 0,864 \\
\hline Out/nov 2004 & 22 & 31 & 32 & 15 & 57 & 0,857 \\
\hline Dez/jan 2005 & 21 & 30 & 29 & 14 & 57 & 0,876 \\
\hline Fev/mar 2005 & 20 & 31 & 29 & 15 & 57 & 0,868 \\
\hline Abr/mai 2005 & 21 & 30 & 29 & 14 & 56 & 0,879 \\
\hline Jun/jul 2005 & 22 & 30 & 30 & 15 & 58 & 0,892 \\
\hline Ago/set 2005 & 21 & 30 & 31 & 14 & 58 & 0,872 \\
\hline Out/nov 2005 & 22 & 30 & 32 & 15 & 57 & 0,872 \\
\hline Dez/jan 2006 & 22 & 30 & 32 & 14 & 58 & 0,878 \\
\hline Fev/mar 2006 & 21 & 30 & 32 & 15 & 57 & 0,876 \\
\hline Abr/mai 2006 & 20 & 30 & 31 & 14 & 57 & 0,864 \\
\hline Jun/jul 2006 & 20 & 30 & 31 & 14 & 58 & 0,866 \\
\hline Ago/set 2006 & 20 & 30 & 31 & 16 & 59 & 0,879 \\
\hline Out/nov 2006 & 20 & 29 & 31 & 16 & 59 & 0,895 \\
\hline $\begin{array}{l}\text { Correlação } \\
\text { participação/ } \\
\text { cobertura }\end{array}$ & 0,169 & 0,429 & 0,894 & 0,597 & 0,431 & \\
\hline
\end{tabular}

Fonte: INSTITUTO, 2006.

Uma provável explicação para a forte dependência do fabricante "C" pela cobertura é o nível de investimentos em mídia de cada fabricante. Enquanto o fabricante "A" é o maior investidor em mídia da categoria, o fabricante "C" não investe nada em mídia, ao mesmo tempo em que mantém uma forte estratégia de investimento na cadeia de distribuição, principalmente em clientes atacadistas, tornando-se mais dependente da cobertura do mercado.
O fabricante "E" possui claramente uma vantagem competitiva sustentável, uma vez que domina mais de 50\% do mercado, com um nível de investimento publicitário inferior a outros competidores. A sua estrutura de distribuição é bastante sofisticada, com uma equipe de vendedores que são funcionários do fabricante e realizam assim o fluxo de vendas e promoção, enquanto distribuidores se responsabilizam pelos fluxos de propriedade, posse física e entrega dos 
produtos aos pontos de vendas de maior poder de compra. No entanto, a grande intensidade distributiva é obtida pelos atacadistas, que vendem esses produtos com um nível de prestação de serviços inferior (o fluxo de promoção no ponto de venda deve ser realizado pelo próprio ponto de venda, e o de informação é prestado em nível bastante inferior). Grosso modo, pode-se dizer que, enquanto os distribuidores são responsáveis pelos maiores pontos de vendas, os atacadistas são responsáveis pelos menores.

Quanto ao modelo de distribuição, os fabricantes "A" e "D" possuem produtos de maior valor agregado e utilizam principalmente distribuidores para atingir os pontos de venda. Possuem uma boa intensidade nos pontos de venda maiores, mas pequena nos menores. Em comum, essas empresas possuem um nível pequeno de atuação nos atacadistas. Já os fabricantes "B" e "C", com produtos de menor valor agregado, adotam uma estratégia contrária, com uma grande rede de clientes atacadistas, de maneira que a sua intensidade é muito alta entre os pontos de venda menores e baixa entre os maiores.

Dentro desse panorama, a estrutura de distribuição do fabricante "E" parece contribuir diretamente para a manutenção da sua vantagem competitiva, ao mesmo tempo em que existem situações em que a cobertura não é um fator único para a obtenção da vantagem competitiva sustentável. Podem-se citar os casos do fabricante "A", cujas variações de cobertura não correspondem a variações de participação de mercado no mesmo sentido, e dos fabricante "B" e "C", que, apesar de uma maior cobertura, possuem menor participação de mercado que os fabricantes "D" e "A", respectivamente.

Tabela 3 - Correlação entre cobertura e participação de mercado para cada fabricante e avaliação do nível de investimentos de mídia de cada um dos fabricantes

\begin{tabular}{lccccc}
\hline & Fabricante A & Fabricante B & Fabricante C & Fabricante D & Fabricante E \\
\hline $\begin{array}{l}\text { Correlação } \\
\text { participação/cobertura }\end{array}$ & 0,169 & 0,429 & 0,894 & 0,597 & 0,431 \\
$\begin{array}{l}\text { Força da correlação } \\
\text { Investimentos em mídia }\end{array}$ & fraca & moderada & forte & moderada & moderada \\
\hline
\end{tabular}

Fonte: INSTITUTO, 2006.

\section{Conclusão}

O estudo e a prática de canais de marketing e distribuição é um tema muito importante e que vem ganhando maior relevância e complexidade, conforme as tecnologias de gestão e de informação avançam. Neste artigo, analisou-se a rede de distribuição como um recurso da firma, em termos da sua capacidade em gerar vantagem competitiva sustentável. Assim, conclui-se que ela pode ser compreendida como um recurso organizacional, uma vez que compreende um subconjunto de indivíduos, controlados pela firma, responsáveis por conceber e implementar estratégias de distribuição, que são tarefas com objetivo de melhorar a eficiência da firma. Conclui-se também que é um recurso heterogeneamente distribuído entre as diversas firmas e, dependendo do mercado a que se faça referência, pode ser um recurso com considerável nível de imobilidade (por exemplo, em mercados de produtos de consumo de alto giro).

Aplicando o modelo baseado em recursos, conclui-se que, ao menos no mercado de bens de consumo, a rede de distribuição é capaz de gerar uma vantagem competitiva sustentável, desde que a firma disponha dos recursos organizacionais complementares necessários a explorá-la, pois: i) seu valor é incontestável, uma vez que ela é necessária para que os seus produtos cheguem ao consumidor final, ii) uma rede realmente eficiente em termos de custo e que leve os produtos da firma a um conjunto de pontos de venda que permita o aproveitamento total do potencial dos seus produtos é um recurso raro e iii) tende a ser um sistema difícil e caro de imitar. 
A análise do caso destinado à verificação do modelo teórico mostrou que a rede de distribuição do fabricante "E" é provavelmente uma fonte de vantagem competitiva sustentável, pois esse fabricante domina mais de 50\% do mercado, com um nível de investimento publicitário inferior a outros competidores. É uma rede bastante sofisticada, de alto valor para a empresa, ao permitir uma cobertura de mercado de aproximadamente $60 \%$. Certamente imitá-la é difícil e caro, uma vez que nenhum dos seus competidores pôde, até o momento, replicar nem a estrutura nem a cobertura resultantes.

\section{Referências}

ANDERSON, E.; DAY, G. S.; RANGAN, V. K. Strategic channel design. Sloan Management Review, v. 38, n. 4, p. 59-69, 1997.

ANSOFF, I. Corporate strategy. Londres: Penguin Books, 1988.

BARNEY, J. B. Firm resources and sustained competitive advantage. Journal of Management, v. 17, n. 1, p. 99-120, 1991.

BARNEY,J. B. Gaining and sustaining the competitive advantage. 2nd ed. New Jersey: Pearson Education, 2001.

COLLINS, D. J.; MONTGOMERY, C. A. Competindo com base em recursos: estratégia na década de 1990. In: HARVARD BUSINESS REVIEW. Estratégia corporativa. 2. ed. Rio de Janeiro: Campus, 2001.

COUGHLAN, A. T. et al. Canais de marketing e distribuição. 6. ed. Porto Alegre: Bookman, 2002.

DIAS, S. R. Estratégia e canais de distribuição. 2. ed. São Paulo: Atlas, 1993.

FRAZIER, G. L.; SUMMERS, J. O. Interfirm influence strategies and their applications within distribution channels. Journal of Marketing, v. 48, n. 3, p. 43-55, 1984.

FOSS, N. J. The resource-based perspective: an assessment and diagnosis of problems. 1997. Disponível em: $<$ http://netec.mcc.ac.uk/WoPEc/data/Papers//aalabbs wp97-1.html>. Acesso em: 5 abr. 2009.

HAMBRICK, D. C. The top management team: key to strategic success. California Management Review, v. 30, n. 1, p. 88-108, 1987.
INSTITUTO AC Nielsen de Pesquisa de Mercado. Relatório on-line disponibilizado pelo sistema Advisory. Dezembro 2006. Disponível em: <http:// br.nielsen.com/company/asociacionesc.shtml>. Acesso em: 5 abr. 2009.

KATO, H. T. Estratégia e canais de marketing. Revista de Administração UNISAL, ano 1, n. 1, p. 1-20, 2004.

KOTLER, P.; ARMSTRONG, G. Princípios de marketing. 5. ed. Rio de Janeiro: Prentice Hall do Brasil, 1993.

MEHTA, R.; ROSENBLOOM, B.; ANDERSON, R. Research note: role of the sales manager in channel management: impact of organizational variables. Journal of Personal Selling \& Sales Management, v. 20, n. 2, p. 81-88, 2000.

MINTZBERG, H. et al. O processo da estratégia. 4. ed. Porto Alegre: Bookman, 2006.

PAZ,H. R. Canales de distribución: estratégia e logística comercial. 2. ed. Buenos Aires: Ugerman, 2000.

PORTER, M. E. Competitive advantage. 2nd ed. New York: The Free Press, 1988.

REED, R.; DE FILLIPPI, R. J.; Causal ambiguity, barrier to imitation and sustainable competitive advantage. The Academy of Management Review, v. 15, n. 1, p. 88-102, 1990.

ROSENBLOOM, B. Canais de marketing: uma visão gerencial. 2. ed. São Paulo: Atlas, 2002.

ROSEMBLOOM, B.; ANDERSON, R. Channel management and sales management: some key interfaces. Academy of Marketing Science Journal, v. 13, n. 3, p. 97-106, 1985.

STERN, L. W. Reflections on channels research. Journal of Retailing, v. 64, n. 1, p. 1-4, 1988.

WEITZ, B.; WANG, Q. Vertical relationships in distribution channels: a marketing perspective. The Antitrust Bulletin, v. 49, n. 4, p. 859-876, 2004.
Recebido: $18 / 08 / 2010$ Received: 08/18/2010

Aprovado: 22/10/2010 Approved: 10/22/2010 